\title{
Mathematics anxiety among STEM and social sciences students: the roles of mathematics self-efficacy, and deep and surface approach to learning
}

\author{
Dmitri Rozgonjuk ${ }^{1,2^{*}}$ (D) Tiina Kraav², Kristel Mikkor ${ }^{2}$, Kerli Orav-Puurand ${ }^{2}$ and Karin Täht ${ }^{2,3}$
}

\begin{abstract}
Background: Although mathematics anxiety and self-efficacy are relatively well-researched, there are several uninvestigated terrains. In particular, there is little research on how mathematics anxiety and mathematics selfefficacy are associated with deep (more comprehensive) and surface (more superficial) approaches to learning among STEM and social sciences students. The aim of the current work was to provide insights into this domain.

Results: Bivariate correlation analysis revealed that mathematics anxiety had a very high negative correlation with mathematics self-efficacy. However, while mathematics anxiety correlated positively with surface approach to learning in the STEM student sample, this association was not statistically significant in the social sciences student sample. Controlled for age and gender, regression analysis showed that lower mathematics self-efficacy and female gender predicted higher mathematics anxiety, while only mathematics self-efficacy predicted mathematics anxiety in the social sciences student sample. Interestingly, approaches to learning were not statistically significant predictors in multivariate analyses when mathematics self-efficacy was included.

Conclusions: The results suggest that mathematics self-efficacy plays a large role in mathematics anxiety. Therefore, one potential takeaway from the results of the current study is that perhaps improving students' mathematics selfefficacy could also be helpful in reducing mathematics anxiety. Since the current study was cross-sectional, it could also be that reducing students' mathematics anxiety could be helpful in boosting their mathematics self-efficacy. Future studies should aim to clarify the causal link in this relationship.
\end{abstract}

Keywords: Mathematics anxiety, Mathematics self-efficacy, Approaches to learning, STEM, Social sciences

\section{Introduction}

One could argue that mathematics is an important component in science, technology, engineering, and mathematics (STEM) education, since most domains rely on applying mathematical thinking. Research on teaching and learning mathematics has received a lot of attention over the years, as mathematical knowledge is a crucial

\footnotetext{
*Correspondence: dmroz@ut.ee

'Department of Molecular Psychology, Institute of Psychology and Education, Ulm University, Helmholtzstraße 8/1, 89081 Ulm, Germany

${ }^{2}$ Institute of Mathematics and Statistics, University of Tartu, Tartu, Estonia

Full list of author information is available at the end of the article
}

factor for students' successful future careers (Claessens \& Engel, 2013; Konvalina, Wileman, \& Stephens, 1983). As mathematics is commonly perceived to be difficult (Fritz, Haase, \& Räsänen, 2019), it has been proposed that instead of instructing the content and practices of mathematics, the main focus should be on students' experience of the discipline and providing mathematical sense-making (Li \& Schoenfeld, 2019). Research in tertiary mathematics education is also a growing field as the role of mathematics in learning other disciplines is widely acknowledged. 
Little research has investigated the relationships between mathematics anxiety, mathematics self-efficacy, and approaches to learning in the context of mathematics education among STEM and social sciences students. Do students with higher mathematics anxiety also have a more superficial approach to learning? Or does mathematics self-efficacy also contribute to a more thoughtful and integrative learning process? Are there significant differences in mathematics self-efficacy, mathematics anxiety, and approaches to learning between STEM and social sciences students? Thus far, these questions have not received a lot of attention in the academic literature. Therefore, the main aim of this study is to provide some insights into the relationships between mathematics anxiety, mathematics self-efficacy, and approaches to learning, and the potential differences in those variables between STEM and social sciences students. While several associations have been investigated in earlier works (see below), this is the first study where the relationships between all these variables are compared among STEM and social sciences students.

\section{Literature overview}

Mathematics anxiety has been described as experiencing feelings of panic and helplessness when asked to solve a mathematical task or problem (Tobias \& Weissbrod, 1980). Psychological as well as physiological symptoms may appear when feeling anxious about mathematics (Chang \& Beilock, 2016). Mathematics anxiety is known as a common problem in K-12 as well as tertiary education (Ashcraft \& Moore, 2009; Luttenberger, Wimmer, \& Paechter, 2018; Yamani, Almala, Elbedour, Woodson, \& Reed, 2018) and, therefore, has received considerable attention as a researched topic among educational scientists (Dowker, Sarkar, \& Looi, 2016; Hoffman, 2010; Jansen et al., 2013). For instance, in the Programme for International Student Assessment (PISA) 2012, across the 34 participating Organisation for Economic Cooperation and Development (OECD) countries, 59\% of the 15-year-old students reported that they often worry that math classes will be difficult for them and 31\% reported they get very nervous doing math problems (OECD, 2013b).

Mathematics anxiety can be caused by several different factors. For instance, unpleasant teaching and assessment strategies for students, like time testing (Ashcraft \& Moore, 2009) and assigning mathematics as punishment (Oberlin, 1982), that are still widely in use in all school levels, may influence the spread of mathematics anxiety. Although mathematics anxiety may have been appearing relatively early in life, it has been shown that there are possibilities to reduce mathematics anxiety in all levels of schooling (Hembree, 1990). As appropriate mathematics-related instruction and teacher's enthusiasm toward mathematics are important in the development of mathematics anxiety of students (Jackson \& Leffingwell, 1999), reduction of pre-service teachers' own mathematics anxiety is crucial and it could be helpful in reducing the students' mathematics anxiety (Gresham, 2007; Vinson, 2001). Applying more active learning (such as group work) may also reduce anxiety (Cooper, Downing, \& Brownell, 2018).

Mathematics anxiety has been shown to be associated with poorer performance in mathematics (Ashcraft \& Faust, 1994; Devine, Fawcett, Szűcs, \& Dowker, 2012; Fan, Hambleton, \& Zhang, 2019). In addition, it has been shown, that mathematics anxiety also correlates with other variables (e.g., learning behavior, self-efficacy) that influence academic performance (Feng, Suri, \& Bell, 2014; McMullan, Jones, \& Lea, 2012). For example, Paechter, Macher, Martskvishvili, Wimmer, and Papousek (2017) investigated psychology students and showed a correlation between mathematics and statistics anxiety and learning behavior. In addition, Royse and Rompf (1992) compared social work and non-social work university students and found that the former had higher levels of mathematics anxiety than the latter group. Nevertheless, there are no studies comparing STEM and social sciences students with regard to mathematics anxiety.

Attitudes toward mathematics is another construct that plays an important role in mathematical studies, as well as its outcomes (Ahmed, Minnaert, Kuyper, \& van der Werf, 2012; House, 2005). Mathematics attitudes and anxiety are often studied together; nevertheless, they cannot be equated with each other. As Zan and Martino (2007) describe, many studies about mathematics attitudes do not provide a clear definition for the construct. It always has an emotional dimension (positive or negative emotional disposition toward mathematics), usually also involving conceptualization of mathematics (Dowker et al., 2016), and/or mathematics-related behavior, depending on the specific research problem. In addition, one may argue that, to some extent, attitudes toward mathematics also reflect mathematics self-efficacy (Yusof \& Tall, 1998). Self-efficacy could be defined as one's belief in one's ability to succeed in specific situations. The academic aspect of this concept is called academic selfefficacy, and is described as an individual's belief that they can successfully achieve at a designated level on an academic task (Bandura, 1997). Mathematics self-efficacy is one's belief about how their own action and effort could lead to success in mathematics (Luttenberger et al., 2018; OECD, 2013b). Higher mathematics selfefficacy has been shown to be correlated with lower mathematics anxiety, more positive, and less negative attitudes toward mathematics (Akin \& Kurbanoglu, 2011). In addition, higher mathematics anxiety is related to more negative attitudes toward mathematics (Vinson, 
2001). These findings underscore the importance of mathematics anxiety in attitudes toward mathematics, as well as mathematics self-efficacy.

More general attitudes toward learning are also important to be considered. Marton and Säljö (1976) referred to a co-existence of intention and process of learning and described deep and surface learning approaches. Students with a deep approach to learning look for the meaning of the studied material and try to relate new knowledge with prior information, whereas students with a surface approach to learning use rote learning and un-meaningful memorization. How students approach to learning in higher education is an important factor when speaking about educational outcomes (Duff, Boyle, Dunleavy, \& Ferguson, 2004; Fryer \& Vermunt, 2018; Maciejewski \& Merchant, 2016). Deep approach to learning is associated with better general academic outcomes, as well as, specifically, better mathematical performance (Murphy, 2017; Postareff, Parpala, \& Lindblom-Ylänne, 2015). Although it is not the sole factor influencing mathematics achievement, it is still important to determine students' approaches to learning mathematics, as it enables educators to analyze and shape the students' classroom experience toward more effective learning.

Little research has been done in the domain of approaches to learning in relation to mathematics anxiety and self-efficacy in tertiary education. Anxiety in general is associated with higher surface and lower deep approach to learning (Marton \& Säljö, 1984). In one study, surface approach to learning has been found to correlate with mathematics anxiety (Bessant, 1995). It has also been demonstrated that students with positive attitudes toward mathematics tend to use more deep and less surface approach when learning mathematics (Alkhateeb \& Hammoudi, 2006; Gorero \& Balila, 2016). Another common finding in educational research is that students who have higher self-efficacy adopt more deep approach to learning (Papinczak, Young, Groves, \& Haynes, 2008; Phan, 2011; Prat-Sala \& Redford, 2010).

There are not many studies investigating the role of deep and surface approaches to learning in mathematics anxiety. Although a study by Bessant (1995) showed that mathematics students scored lower on mathematics anxiety measure than psychology/sociology students, the relations between mathematics anxiety and approaches to learning in STEM and social sciences students is a largely unexplored area.

\section{Conceptual framework}

Several studies have aimed to explain the potential causes for mathematics anxiety. It has been proposed that the origins of mathematics anxiety could be categorized into three groups (Baloglu \& Kocak, 2006): situational, dispositional, and environmental factors. Situational factors are direct stimuli related to feelings of anxiety in relation to mathematics. Dispositional factors include individual characteristics, such as personality traits; for instance, it has been shown that people with higher trait neuroticism (the tendency to experience negative effect; McCrae \& Costa, 2003) worry more and tend to be more anxious in general (Costa \& McCrae, 1985), although this typically decreases with age (Mõttus \& Rozgonjuk, 2019). Finally, environmental factors include prior perceptions, attitudes, and experiences that may have affected the individual (Baloglu \& Kocak, 2006).

In the current work, mathematics self-efficacy as well as approaches to learning could be conceptualized as environmental factors that could potentially affect the development of mathematics anxiety. Furthermore, students' age, gender, and the curricula could be considered as environmental factors potentially affecting mathematics anxiety (Baloglu \& Kocak, 2006).

\section{Aims and hypotheses}

The general aim of this study is to investigate how mathematics anxiety and self-efficacy, as well as approaches to learning (deep and surface), are related to each other. Furthermore, these relationships are also compared across STEM and social sciences student samples. Based on the previous literature, we have posed some hypotheses that are rather confirmatory of previous findings. Based on the previous literature, we hypothesize the following:

\section{H1: Mathematics anxiety and mathematics self-efficacy are negatively correlated.}

Previously it has been demonstrated that mathematics anxiety and self-efficacy are inversely associated (Akin \& Kurbanoglu, 2011; Vinson, 2001).

H2: Mathematics anxiety is positively correlated with surface approach to learning and negatively with deep approach to learning. Even though one study found that mathematics anxiety correlates positively with surface approach to learning (Bessant, 1995), it would also be natural to assume that deep approach to learning is negatively associated with mathematics anxiety, since typically surface and deep approaches to learning are inversely correlated (Rozgonjuk, Saal, \& Täht, 2018).

H3: Mathematics self-efficacy is positively associated with deep and negatively with surface approach to learning. It has previously been shown that high selfefficacy, in general, is associated with more deep and less surface approach to learning (Chou \& Liang, 2012; 
Papinczak et al., 2008). Therefore, it would be logical to assume that also in the context of mathematics, these constructs would be correlated.

H4: STEM students have less mathematics anxiety than social sciences students. Previously, Bessant (1995) have demonstrated that mathematics students had lower scores on mathematics anxiety measure than psychology/sociology students. However, our study goes beyond comparing only mathematics students, and includes students from other disciplines (e.g., biology) as well, forming a more heterogeneous STEM student group.

H5: Approaches to learning and mathematics selfefficacy predict mathematics anxiety when age and gender are controlled for. Based on previous research and hypotheses mentioned above, there is evidence to believe that the associations between approaches to learning, mathematics self-efficacy, and mathematics anxiety would hold also when covariates are included.

There is relatively little research in this domain and knowing the associations between these variables may help educators to improve and adjust their teaching strategies to potentially improve the learning process. The results of this study aim to outline the important predictors of mathematics anxiety, and, therefore, expand the existing research in this field of study, and influence future teaching strategies. The results of this work could be helpful for the teacher/lecturer when he/ she aims toward reducing mathematics anxiety by, e.g., using teaching strategies that could enhance deeper (and less surface) approach to learning, increase mathematics self-efficacy, or both.

\section{Material and methods}

\section{Sample and procedure}

The study participants were students who either took an introductory calculus course (dealing with more elaborate topics than in secondary education) for university students or an introductory statistical modeling course at a major Estonian university. Importantly, these courses were mandatory in order to complete the student's curriculum and, in most cases, were prerequisite courses for other courses in the curriculum. While most of the students in the introductory calculus course were STEM curricula students, mainly psychology and political sciences majors were enrolled in the statistical modeling course. However, because it is possible to take these courses as electives as well, students with various backgrounds could participate in these courses. This means that, theoretically, both student groups could enroll in either the calculus or statistical modeling course. For instance, as could be seen in Supplementary Table 1 there are some Economics students who enrolled in a
Calculus course, while all other social sciences students were enrolled in the statistical modeling course. Students' responses across variables of interest across curricula are depicted in Supplementary Figures 1 to 4 .

The data were collected during the start of both courses, in September 2019. Students were asked to take part in a web survey which aimed to investigate the role of different factors in mathematics education. Participation in the study was voluntary, anonymous, and in line with the Helsinki Declaration.

In total, there were 358 responses. However, many rows were empty or most of the data were missing, after some initial data cleaning, 234 rows of responses were kept. The reason for the aforementioned "missing data" lies in the fact that whenever a person opens the questionnaire environment, this gets logged as a response row. However, it does not necessarily mean that a person provides any responses to the questionnaire. Therefore, as mentioned, out of 358 rows logged, only 234 were actually partially or fully filled in with responses. Finally, because $n=3$ people did not specify their major, we excluded those rows. Therefore, the effective sample comprised 231 students (age $\mathrm{M}=21.39, \mathrm{SD}=5.12 ; 79$ (34.2\%) men, 152 (65.8\%) women). There were 147 (63.6\% of total sample) STEM students (age $M=20.55, \mathrm{SD}=4.51 ; 57$ men, 90 women), and $84(36.4 \%)$ social sciences students (age $M=22.87$, $\mathrm{SD}=5.78 ; 22$ men, 62 women).

\section{Measures}

We queried about the study participants' sociodemographic variables (e.g., age, gender, curriculum/ major), mathematics anxiety and mathematics selfefficacy, and approaches to learning (deep and surface).

\section{Mathematics anxiety}

Mathematics anxiety was measured with the 5-item mathematics anxiety questionnaire used in the international PISA 2012 survey (OECD, 2013a). Students were asked to assess on a 4-point scale $(1=$ strongly disagree to $4=$ strongly agree) the extent of agreement with the following statements: (1) I often worry that mathematics classes will be difficult for me; (2) I get very tense when I have to do mathematics homework; (3) I get very nervous doing mathematics problems; (4) I feel helpless when doing a mathematics problem; (5) I worry that I will get poor grades in mathematics. The psychometric properties of this scale in an adolescent population could be found in OECD report (2014; Table 16.7 on page 320). As a side comment, we opted for using this measure as opposed to, e.g., the Abbreviated Mathematics Anxiety Scale (AMAS; Hopko, Mahadevan, Bare, \& Hunt, 2003), because the PISA-study mathematics anxiety scale fits better with contemporary classroom where the role of digitalization is increasing (e.g., the AMAS 
items include words like "book" and "blackboard," but not digital resources). Secondly, PISA mathematics anxiety scale has demonstrated good psychometric properties, it has probably been administered in a larger variety of cultural settings (as opposed to the AMAS), and it has been validated against mathematics aptitude test in all these cultures (e.g., see the report by OECD (2014), p. 320, Table 16.7, ANXMAT). Finally, in all PISA survey questionnaires, stringent quality-assurance mechanisms are implemented by experts in translation, sampling, and data collection, resulting in a high degree of reliability and validity (OECD, 2017). Cronbach's alpha for the effective sample of this measure was very good, $\alpha=0.90$.

\section{Mathematics self-efficacy}

Mathematics self-efficacy was measured with three items, measuring the extent of agreement on a fourpoint scale $(1=$ strongly disagree to $4=$ strongly agree $)$ from Yusof and Tall (1998). All items from the mathematics self-efficacy scale (Yusof \& Tall, 1998) were translated into Estonian by the members of our mathematics education team and were reviewed by a professional Estonian philologist. The questionnaire was then translated back into English by another translator, and the backtranslated English version was reviewed by an Englishspeaking student in order to estimate the content and the similarities between the original and the backtranslated items. The items were the following: (1) I usually understand a mathematical idea quickly; (2) I have to work very hard to understand mathematics; (3) I can connect mathematical ideas that I have learned. Cronbach's alpha for this three-item measure was $\alpha=0.83$.

\section{Approaches to learning}

Approaches to learning were measured with the Estonian adaptation of the Revised Study Process Questionnaire (Biggs, Kember, \& Leung, 2001; Valk \& Marandi, 2005). It is a 16-item measure ( 8 items for deep and 8 items for surface approach to learning) that measures deep and surface approaches to learning on a five-point scale $(1=$ do not agree at all to $5=$ totally agree $)$. Example items for the deep approach to learning scale are as follows: I find most new topics interesting and often spend extra time trying to obtain more information about them, and I learn because I want to understand the world. Example items for the surface approach to learning scale are as follows: I see no point in learning material which is not likely to be in the examination, and In case of difficult topics, learning by rote is one way to pass an exam. The internal consistency of deep and surface approaches to learning were acceptable, Cronbach's $\alpha=$ 0.71 for both scales.

\section{Analysis}

Data analysis was conducted in the $\mathrm{R}$ software version 3.5.3 (R Core Team, 2020). As mentioned in the "Sample and procedure" section, we first removed the data rows that were not valid responses (empty rows) or where people did not specify their major $(n=3)$. After this procedure, there were no missing data in key variables. Internal consistency statistics were calculated with the alpha() function from the psych package (Revelle, 2018). Since the sample sizes were not equal, Mann-Whitney $U$ tests to analyze the potential group differences between STEM and social sciences students in age, math anxiety and self-efficacy, and deep and surface approach to learning were used. Chi-square test was used to see if there are differences in gender distribution among those student groups.

We then computed descriptive statistics and conducted Spearman correlation analysis (with $p$ values adjusted for multiple testing with the Holm's method), using the rcorr.adjust() function from the RcmdrMisc package (Fox, 2020). Finally, we computed regression models where mathematics anxiety was treated as the outcome variable, either surface or deep approach to learning as the predictor, age and sex were covariates, and we also computed additional regression models where mathematics self-efficacy was additionally included as a predictor variable. We ran these analyses for the whole sample, as well as for STEM and social sciences students separately.

The data as well as the analysis script are included with this work as Supplementary Materials.

\section{Results}

Firstly, we analyzed if STEM and social sciences students had group differences in key variables. There were no statistically significant group differences in deep and surface approaches to learning, mathematics anxiety, as well as in gender distribution (all $p s>0.01$ ). However, the social sciences student group was slightly older $(M=22.87, \mathrm{SD}=$ 5.78) than the STEM student group $(M=20.55$, SD $=$ 4.51), $W=9742, p<0.001$. In addition, STEM students $(M=8.39, \mathrm{SD}=1.92)$ had higher mathematics selfefficacy scores than social sciences students $(M=7.77$, SD $=2.03), W=5080.50, p=0.023$.

\section{Descriptive statistics and correlations for mathematics anxiety and self-efficacy, and approaches to learning} The descriptive statistics and Spearman correlation coefficients between the variables are in Table 1 .

According to Table 1, mathematics anxiety was very strongly negatively correlated to mathematics selfefficacy across all samples. Additionally, surface learning was positively significantly associated with mathematics anxiety in the total and STEM student sample, but it 
Table 1 Descriptive statistics and correlations for math anxiety and self-efficacy, approaches to learning, and age

\begin{tabular}{|c|c|c|c|c|c|c|c|c|}
\hline Sample $(N)$ & $M$ & SD & Min & Max & 1 & 2 & 3 & 4 \\
\hline \multicolumn{9}{|l|}{ Total sample $(N=231)$} \\
\hline 1. Math anxiety & 11.06 & 3.77 & 5 & 20 & 1 & & & \\
\hline 2. Math self-efficacy & 8.17 & 1.98 & 3 & 12 & $-0.769^{* * *}$ & 1 & & \\
\hline 3. SAL & 19.00 & 4.53 & 9 & 33 & $0.251^{* * *}$ & $-0.210^{*}$ & 1 & \\
\hline 4. DAL & 27.51 & 4.06 & 12 & 36 & -0.115 & 0.085 & $-0.318^{* * *}$ & 1 \\
\hline 5. Age & 21.39 & 5.12 & 17 & 51 & 0.128 & $-0.202^{*}$ & -0.113 & 0.167 \\
\hline \multicolumn{9}{|c|}{ STEM sample $(N=147)$} \\
\hline 1. Math anxiety & 10.73 & 3.64 & 5 & 20 & 1 & & & \\
\hline 2. Math self-efficacy & 8.39 & 1.92 & 3 & 12 & $-0.759^{* * *}$ & 1 & & \\
\hline 3. SAL & 19.03 & 4.50 & 10 & 31 & $0.317^{* * *}$ & $-0.233^{*}$ & 1 & \\
\hline 4. DAL & 27.17 & 4.23 & 12 & 36 & -0.215 & 0.160 & $-0.351^{* * *}$ & 1 \\
\hline 5. Age & 20.55 & 4.51 & 17 & 45 & 0.125 & -0.206 & -0.025 & 0.083 \\
\hline \multicolumn{9}{|c|}{ Social sciences sample $(N=84)$} \\
\hline 1. Math anxiety & 11.64 & 3.94 & 5 & 20 & 1 & & & \\
\hline 2. Math self-efficacy & 7.77 & 2.03 & 3 & 12 & $-0.802^{* * *}$ & 1 & & \\
\hline 3. SAL & 18.93 & 4.60 & 9 & 33 & 0.148 & -0.182 & 1 & \\
\hline 4. DAL & 28.11 & 3.68 & 20 & 36 & 0.031 & -0.005 & -0.246 & 1 \\
\hline 5. Age & 22.87 & 5.78 & 19 & 51 & -0.059 & 0.059 & $-0.319^{*}$ & 0.208 \\
\hline
\end{tabular}

SAL surface approach to learning; DAL deep approach to learning

$P$ values are adjusted for multiple testing with the Holm's method

${ }^{*} p<0.05$

${ }^{* *} p<0.01$

${ }_{* * *}^{*} p<0.001$

was not significant among social sciences students. Deep approach to learning and age were not statistically significantly associated with mathematics anxiety.

Mathematics self-efficacy was negatively significantly associated with surface approach to learning in total and STEM student samples, but not in social sciences students. Mathematics self-efficacy did not correlate with deep approach to learning.

Surface approach to learning was negatively correlated to deep approach to learning in total and STEM student samples (but not in social sciences student sample) and had a statistically significant negative correlation with age only in social sciences student sample. Deep approach to learning did not correlate with age.

\section{Which factors predict mathematics anxiety?}

Next, we computed several regression models where mathematics anxiety was treated as the outcome variable. We computed models for three samples of students: the full sample $(N=231)$, the STEM student sample $(N=147)$, and the social sciences students $(N=$ 84). For each sample of students, we computed two models. Model 1 included age, gender, and surface and deep approaches to learning as predictors. In model 2, mathematics self-efficacy was added as an additional predictor. For the full sample, we also included the student group (STEM vs social sciences) as a predictor.

According to results in Table 2, when regression models are computed across the full sample, female students tend to have greater mathematics anxiety than male students. Approaches to learning, age, and being a STEM versus social sciences student did not predict mathematics anxiety. Finally, including the mathematics self-efficacy variable was negatively associated with mathematics anxiety in this multivariate model. In addition, it seems that mathematics self-efficacy explains a large proportion of mathematics anxiety, as inclusion of this variable improved the explained variance by almost $50 \%$ in the regression model full sample level.

However, the regression analysis results are somewhat different when the sample is broken down into the STEM and social sciences student group. In STEM students, it seems higher mathematics anxiety is associated with older age, female gender, and more surface and less deep approach to learning. However, when mathematics self-efficacy is included in the model, only gender and mathematics self-efficacy effects are significant.

Interestingly, when mathematics self-efficacy is not included as a predictor of mathematics anxiety, there are no statistically significant predictors in the social sciences student sample; however, once it is included in the regression 
Table 2 Results for regression models where age and gender, approaches to learning, and mathematics self-efficacy predict mathematics anxiety in STEM and social sciences student samples

\begin{tabular}{|c|c|c|c|c|c|c|}
\hline \multirow[b]{3}{*}{ Predictors } & \multicolumn{6}{|c|}{ Dependent variable: math anxiety } \\
\hline & \multicolumn{2}{|l|}{ Full sample } & \multicolumn{2}{|l|}{ STEM sample } & \multicolumn{2}{|c|}{ Social sciences sample } \\
\hline & Model 1 & Model 2 & Model 1 & Model 2 & Model 1 & Model 2 \\
\hline Intercept & $5.853^{*}(2.562)$ & $20.756^{* * *}(1.888)$ & $5.274(2.865)$ & $20.432^{* * *}(2.313)$ & $4.993(4.716)$ & $21.688^{* * *}(3.206)$ \\
\hline Age & $0.086(0.048)$ & $0.008(0.032)$ & $0.147^{*}(0.062)$ & $-0.016(0.045)$ & $0.007(0.077)$ & $0.038(0.047)$ \\
\hline Gender & $1.407^{* *}(0.510)$ & $1.207^{* * *}(0.335)$ & $1.927^{* *}(0.576)$ & $1.682^{* * *}(0.397)$ & $0.284(0.995)$ & $0.271(0.605)$ \\
\hline SAL & $0.183^{* *}(0.056)$ & $0.037(0.038)$ & $0.179 * *(0.066)$ & $0.053(0.047)$ & $0.185(0.100)$ & $0.013(0.062)$ \\
\hline DAL & $-0.074(0.064)$ & $-0.036(0.042)$ & $-0.150^{*}(0.072)$ & $-0.065(0.050)$ & $0.089(0.126)$ & $0.018(0.077)$ \\
\hline Student group & $-0.628(0.507)$ & $0.104(0.335)$ & & & & \\
\hline Math self-efficacy & & $-1.427^{* * *}(0.083)$ & & $-1.350^{* * *}(0.107)$ & & $-1.560^{* * *}(0.134)$ \\
\hline \multicolumn{7}{|l|}{ Model statistics } \\
\hline N & 231 & 231 & 147 & 147 & 84 & 84 \\
\hline$R^{2}$ & 0.116 & 0.622 & 0.183 & 0.615 & 0.046 & 0.652 \\
\hline Adjusted $R^{2}$ & 0.097 & 0.612 & 0.160 & 0.601 & -0.002 & 0.630 \\
\hline Residual SE (df) & $3.584(225)$ & $2.350(224)$ & $3.338(142)$ & $2.300(141)$ & 3.945 (79) & $2.399(78)$ \\
\hline$F(d f)$ & $5.927^{* * *}(5 ; 225)$ & $61.352^{* * *}(6 ; 224)$ & $7.968^{* * *}(4 ; 142)$ & $45.044^{* * *}(5 ; 141)$ & $0.961(4 ; 79)$ & $29.205^{* * *}(5 ; 78)$ \\
\hline
\end{tabular}

Regression coefficients are displayed (with standard errors in parentheses)

$S A L$ surface approach to learning; DAL deep approach to learning

${ }^{*} p<0.05$

${ }^{* *} p<0.01$

${ }^{* * *} p<0.001$

model, mathematics self-efficacy is statistically significantly and negatively associated with mathematics anxiety.

\section{Discussion}

The aim of the current study was to investigate the relationships between mathematics anxiety, mathematics self-efficacy, and approaches to learning (deep and surface) among STEM and social sciences students. We had posed several hypotheses to meet that aim.

Based on the literature (Akin \& Kurbanoglu, 2011; Vinson, 2001), we expected mathematics anxiety and mathematics self-efficacy to have a negative association (H1). This hypothesis found support from the data. The very high negative correlation of $r=-0.768$ (across the full sample) suggests that these variables explain each other's variance relatively well. These results were expected, since students who perceive that they can succeed in mathematics and who have a more positive attitude toward this topic, should experience less anxiety; furthermore, as mentioned earlier, these findings are coherent with previous research (Akin \& Kurbanoglu, 2011).

Our second hypothesis $(\mathrm{H} 2)$ regarded the relationship between mathematics anxiety and approaches to learning. Specifically, we expected that mathematics anxiety correlates positively with surface approach to learning and negatively with deep approach to learning. While surface approach to learning should be associated with increased and deep approach to learning with decreased anxiety in general, a study found that only higher levels of surface approach to learning correlated with more mathematics anxiety (Bessant, 1995). The results of the current study supported this hypothesis on the full and STEM student sample level; however, surface approach to learning did not correlate significantly with mathematics anxiety in social sciences students. Furthermore, deep approach to learning was negatively correlated with mathematics anxiety in the STEM student sample. This is the first study demonstrating that there are discrepancies in approaches to learning in association with mathematics anxiety between STEM and social sciences students. Although it is hard to explain these discrepancies based on our data, it is certainly a topic that needs to be pursued further.

According to the third hypothesis $(\mathrm{H} 3)$, we expected mathematics self-efficacy to be positively correlated with deep and negatively with surface approach to learning, in line with some previous findings (Alkhateeb \& Hammoudi, 2006; Gorero \& Balila, 2016). This hypothesis found partial support from the data. Deep approach to learning was not associated with mathematics selfefficacy, while surface approach to learning had a negative correlation with mathematics self-efficacy on the full and STEM student sample level.

We expected that STEM students have less mathematics anxiety than social sciences students in our fourth hypothesis (H4). Royse and Rompf (1992) compared groups of students who did and did not study social 
work and found that the former had higher mathematics anxiety. However, this was not the case in the current study. STEM and social sciences students did not differ from each other in group comparison analysis. Therefore, this hypothesis did not find support from data. These results are surprising, since one may logically think that if a student chooses to major in a subject that has a strong mathematics component, the student's anxiety toward mathematics could be lower than among students who choose a curriculum where the share of mathematics may be rather small (on an undergraduate level). Furthermore, STEM students are more likely to have mathematics in different courses throughout their studies as well as professionally after graduation. Therefore, these results are certainly interesting, since they demonstrate that STEM and social sciences students are as much or as little anxious toward mathematics.

Finally, to understand how mathematics anxiety would be predicted from approaches to learning and mathematics self-efficacy when age and gender are controlled for, we conducted regression models on the total, STEM, and social sciences student samples. We hypothesized that approaches to learning and mathematics selfefficacy predict mathematics anxiety, also when age and gender are controlled for (H5). The regression model results showed that among STEM student sample, older age, female gender, higher surface, and lower deep approach to learning predicted higher mathematics anxiety. However, when mathematics self-efficacy was included in the model, only female gender and lower mathematics self-efficacy were significant predictors of mathematics anxiety. Gender differences are somewhat in line with research finding that female students tend to experience more anxiety in STEM classroom settings (Pelch, 2018). Interestingly, only lower mathematics selfefficacy predicted higher mathematics anxiety in social sciences student sample.

One potential takeaway from the results of this study is that in order to lower one's mathematics anxiety, it could be necessary to boost one's mathematics selfefficacy. However, this may prove to be a rather difficult task, since there is a potential problem of a "vicious circle:" one's mathematics self-efficacy may be dependent on one's performance in mathematics, and vice versa (Carey, Hill, Devine, \& Szücs, 2016). Therefore, if a student performs well on a mathematics task, their selfefficacy may get a boost, consequently lowering mathematics-related anxiety. On the other hand, if a student performs poorly, their self-efficacy may drop, followed by increased anxiety. Mathematics anxiety, in turn, could further hamper one's mathematics performance, resulting in poorer perceived self-efficacy. It would be, therefore, necessary to further study-preferably experimentally and in a longitudinal study design-how working with one's mathematics self-efficacy could be helpful against mathematics anxiety.

While we discussed the association between mathematics anxiety and self-efficacy, it is nevertheless noteworthy that approaches to learning seem to play a significant role in mathematics anxiety among STEM students. Somewhat coherent with previous findings, more surface approach to learning predicted more mathematics anxiety (Bessant, 1995). These results suggest that perhaps-at least among STEM students-there is a possibility to tailor the classroom experience so that it would promote more synthesis of study materials, and decrease fact-based, rote-learning. STEM subjects likely have more universal facts (e.g., equations, proofs) to be learned, possibly promoting superficial learning. Here, too, could be a potentially vicious circle in play: a student who has to study materials that may seemingly be isolated facts, could implement rote-learning. This results in superficial knowledge, which may not prove to be useful when synthesis with other materials is needed. In turn, this may lead to poor performance and higher mathematics anxiety due to that. As discussed earlier, mathematics self-efficacy also likely plays a crucial role in this process. On the other hand, this reasoning does not entirely explain why approaches to learning did not predict mathematics anxiety among social sciences students. It could be that STEM students differ in how they perceive mathematics in general due to having to use this more in their studies. We believe that this should receive more attention in future research.

The main contribution of this study is providing insights into the potential role of mathematics self-efficacy, and deep and surface approaches to learning in mathematics anxiety in STEM and social sciences students. All in all, it could be inferred from this study that while surface approach to learning may be, to some extent, an important factor possibly predicting mathematics anxiety, the role of mathematics self-efficacy should be further studied in combination with approaches to learning in order to understand mathematics anxiety. It could be further hypothesized that by improving mathematics self-efficacy, it could also be helpful in reducing mathematics anxiety, as well as surface approaches to learning. Interestingly, while STEM and social science students differ in attitudes toward mathematics (with STEM students scoring higher), there were no differences in mathematics anxiety between these student groups.

There are limitations that need to be mentioned. Firstly, we used self-reports in our study. It could be helpful to include other important variables, such as grades and test scores, to complement the results. In addition, methods such as experience sampling may also provide more valid results (Lehtamo, Juuti, Inkinen, \& Lavonen, 2018). Secondly, there were significantly fewer 
social sciences students than STEM students in the total sample, and social sciences students were slightly older than STEM students. Although age was accounted for in multivariate analyses, future studies should aim toward equal sample sizes as well as higher similarity in other demographic characteristics (e.g., age, gender). A third limitation was the absence of controlling for students' prior academic ability (e.g., grade point average, course grades, ability test results). It could be that there are inherent differences between the past performance in mathematicsrelated courses and mathematics self-efficacy and anxiety. Future works should include variables of prior academic ability as control variables. In addition, future works could also collect data among STEM and social sciences students across multiple semesters, providing more robust results. The fourth limitation regards the use of the mathematics anxiety scale that has been validated in a sample of adolescents. Some additional measures of mathematics anxiety designed for tertiary-education settings, such as the AMAS (Hopko et al., 2003), could further validate the findings. Finally, future studies could also include other external factors to models predicting mathematics anxiety (MartinHansen, 2018).

\section{Conclusions}

In conclusion, we found that STEM and social sciences students do not differ largely with regard to mathematics anxiety, while STEM students do have higher mathematics self-efficacy. It may be that surface approach to learning plays a larger role in mathematics anxiety in STEM students than in social sciences students. This is the first work to investigate the differences between STEM and social sciences students in mathematics anxiety and selfefficacy, as well as deep and surface approaches to learning. The results could be helpful for mathematics educators, as it is relevant for them to learn about and understand the interplay between deep and surface approach to learning, mathematics anxiety and selfefficacy, and students' curricula. It could be that improving students' mathematics self-efficacy, as well as facilitating more synthesis among the learned materials could help as a remedy against mathematics anxiety. This, however, should be investigated in future research that, preferably, implements an experimental and longitudinal study design.

\section{Supplementary information}

Supplementary information accompanies this paper at https://doi.org/10. 1186/s40594-020-00246-z.

Additional file 1: Supplementary Table 1 Grouping of students to social sciences/STEM by self-reported curricula, and the distribution of students' curricula by course taken Notes. LT_Calc1 = Calculus I (LTMS.00.003); MT_Calc1 = Calculus I (MTMM.00.340); SH_StatM = Statistical Modeling (SHSH.00.002). Supplementary Figure 1: Students' mathematics anxiety summed scores plotted by curricula. Note: points are jittered on the graph (with the geom_jitter() function). Supplementary Figure 2: Students' mathematics self-efficacy summed scores plotted by curricula. Note: points are jittered on the graph (with the geom_jitter() function). Supplementary Figure 3: Students' deep approach to learning summed scores plotted by curricula. Note: points are jittered on the graph (with the geom_jitter() function). Supplementary Figure 4: Students' surface approach to learning summed scores plotted by curricula. Note: points are jittered on the graph (with the geom_jitter() function). Math anxiety study

\section{Acknowledgements}

N/A

Authors' contributions

DR designed the study, collected and analyzed the data, and wrote the first draft; TK designed the study, collected the data, and revised the manuscript; KOP collected the data and revised the manuscript; KM collected the data, and revised the manuscript; $K T$ collected the data, and revised the manuscript. The author(s) read and approved the final manuscript.

\section{Funding}

This work did not receive funding. Open access funding provided by Projekt DEAL.

Availability of data and materials

The data as well as analysis script are available among the supplementary materials.

Competing interests

The authors declare that they have no competing interests.

\section{Author details}

${ }^{1}$ Department of Molecular Psychology, Institute of Psychology and Education, Ulm University, Helmholtzstraße 8/1, 89081 Ulm, Germany. ${ }^{2}$ Institute of Mathematics and Statistics, University of Tartu, Tartu, Estonia. ${ }^{3}$ Institute of Psychology, University of Tartu, Tartu, Estonia.

Received: 3 March 2020 Accepted: 9 August 2020

Published online: 07 September 2020

\section{References}

Ahmed, W., Minnaert, A., Kuyper, H., \& van der Werf, G. (2012). Reciprocal relationships between math self-concept and math anxiety. Learning and Individual Differences, 22(3), 385-389. https://doi.org/10.1016/j.lindif.2011.12. 004

Akin, A., \& Kurbanoglu, I. N. (2011). The relationships between math anxiety, math attitudes, and self-efficacy: A structural equation model. Studia Psychologica, 53(3), 263-273.

Alkhateeb, H. M., \& Hammoudi, L. (2006). Attitudes toward and approaches to learning first-year university mathematics. Perceptual and Motor Skills, 103(1), 115-120. https://doi.org/10.2466/pms.103.1.115-120

Ashcraft, M. H., \& Faust, M. W. (1994). Mathematics anxiety and mental arithmetic performance: An exploratory investigation. Cognition \& Emotion, 8(2), 97-125. https://doi.org/10.1080/02699939408408931

Ashcraft, M. H., \& Moore, A. M. (2009). Mathematics anxiety and the affective drop in performance. Journal of Psychoeducational Assessment, 27(3), 197-205. https://doi.org/10.1177/0734282908330580

Baloglu, M., \& Kocak, R. (2006). A multivariate investigation of the differences in mathematics anxiety. Personality and Individual Differences, 40(7), 1325-1335. https://doi.org/10.1016/j.paid.2005.10.009

Bandura, A. (1997). Self-efficacy: The exercise of control. W.H. Freeman.

Bessant, K. C. (1995). Factors associated with types of mathematics anxiety in college students. Journal for Research in Mathematics Education, 26(4), 327. https://doi.org/10.2307/749478

Biggs, J., Kember, D., \& Leung, D. Y. (2001). The revised two-factor study process questionnaire: R-SPQ-2F. Br J Educ Psychol, 71(Pt 1), 133-149. https://doi.org/ 10.1348/000709901158433

Carey, E., Hill, F., Devine, A., \& Szücs, D. (2016). The chicken or the egg? The direction of the relationship between mathematics anxiety and mathematics 
performance. Frontiers in Psychology, 6. https://doi.org/10.3389/fpsyg.2015. 01987

Chang, H., \& Beilock, S. L. (2016). The math anxiety-math performance link and its relation to individual and environmental factors: A review of current behavioral and psychophysiological research. Current Opinion in Behavioral Sciences, 10, 33-38. https://doi.org/10.1016/j.cobeha.2016.04.011

Chou, C., \& Liang, J. (2012). Exploring the structure of science self-efficacy: A model built on high school students' conceptions of learning and approaches to learning in science. The Asia-Pacific Education Researcher, 21(1), 83-91.

Claessens, A., \& Engel, M. (2013). How important is where you start? Early mathematics knowledge and later school success. Teachers College Record, 115, 060306

Cooper, K. M., Downing, V. R., \& Brownell, S. E. (2018). The influence of active learning practices on student anxiety in large-enrollment college science classrooms. International Journal of STEM Education, 5(1), 23. https://doi.org/ 10.1186/s40594-018-0123-6

Costa, P. T., \& McCrae, R. R. (1985). Hypochondriasis, neuroticism, and aging: When are somatic complaints unfounded? American Psychologist, 40(1), 1928. https://doi.org/10.1037/0003-066X.40.1.19

Devine, A., Fawcett, K., Szűcs, D., \& Dowker, A. (2012). Gender differences in mathematics anxiety and the relation to mathematics performance while controlling for test anxiety. Behavioral and Brain Functions, 8, 33 http://www. behavioralandbrainfunctions.com/content/8/1/33.

Dowker, A., Sarkar, A., \& Looi, C. Y. (2016). Mathematics anxiety: What have we learned in 60 years? Frontiers in Psychology, 7. https://doi.org/10.3389/fpsyg. 2016.00508

Duff, A., Boyle, E., Dunleavy, K., \& Ferguson, J. (2004). The relationship between personality, approach to learning and academic performance. Personality and Individual Differences, 36(8), 1907-1920. https://doi.org/10.1016/j.paid.2003.08. 020

Fan, X., Hambleton, R. K., \& Zhang, M. (2019). Profiles of mathematics anxiety among 15-year-old students: A cross-cultural study using multi-group latent profile analysis. Frontiers in Psychology, 10, 1217. https://doi.org/10.3389/fpsyg. 2019.01217

Feng, S., Suri, R., \& Bell, M. (2014). Does classical music relieve math anxiety? Role of tempo on price computation avoidance. Psychology \& Marketing, 31(7), 489-499. https://doi.org/10.1002/mar.20710

Fox, J. (2020). RcmdrMisc: R Commander Miscellaneous Functions (2.7-0) [Computer software]. https://CRAN.R-project.org/package $=$ RcmdrMisc

Fritz, A., Haase, V. G., \& Räsänen, P. (2019). International handbook of mathematical learning difficulties: From the laboratory to the classroom. https://doi.org/10. 1007/978-3-319-97148-3

Fryer, L. K., \& Vermunt, J. D. (2018). Regulating approaches to learning: Testing learning strategy convergences across a year at university. British Journal of Educational Psychology, 88(1), 21-41. https://doi.org/10.1111/bjep.12169

Gorero, L. G., \& Balila, E. A. (2016). Mediated moderation effects of gender, year level and learning approaches on attitude, teaching efficacy and mathematics achievement of education students. Journal of International Scholars Conference - EDUCATION/SOCIAL SCIENCES, 1(2), 96-105.

Gresham, G. (2007). A study of mathematics anxiety in pre-service teachers. Early Childhood Education Journal, 35(2), 181-188. https://doi.org/10.1007/s10643007-0174-7

Hembree, R. (1990). The nature, effects, and relief of mathematics anxiety. Journal for Research in Mathematics Education, 21(1), 33. https://doi.org/10.2307/ 749455

Hoffman, B. (2010). "I think I can, but I'm afraid to try": The role of self-efficacy beliefs and mathematics anxiety in mathematics problem-solving efficiency. Learning and Individual Differences, 20(3), 276-283. https://doi.org/10.1016/j. lindif.2010.02.001

Hopko, D. R., Mahadevan, R., Bare, R. L., \& Hunt, M. K. (2003). The abbreviated math anxiety scale (AMAS): Construction, validity, and reliability. Assessment, 10(2), 178-182. https://doi.org/10.1177/1073191103010002008

House, J. (2005). Mathematics beliefs and achievement of adolescent students in Japan: Results from the TIMSS 1999 assessment. Psychological Reports, 97, 717-720.

Jackson, C. D., \& Leffingwell, R. J. (1999). The role of instructors in creating math anxiety in students from kindergarten through college. The Mathematics Teacher, 92(7), 583-586.

Jansen, B. R. J., Louwerse, J., Straatemeier, M., Van der Ven, S. H. G., Klinkenberg, S., \& Van der Maas, H. L. J. (2013). The influence of experiencing success in math on math anxiety, perceived math competence, and math performance. Learning and Individual Differences, 24, 190-197. https://doi.org/10.1016/j. lindif.2012.12.014

Konvalina, J., Wileman, S. A., \& Stephens, L. J. (1983). Math proficiency: A key to success for computer science students. Communications of the ACM, 26(5), 377-382. https://doi.org/10.1145/69586.358140

Lehtamo, S., Juuti, K., Inkinen, J., \& Lavonen, J. (2018). Connection between academic emotions in situ and retention in the physics track: Applying experience sampling method. International Journal of STEM Education, 5(1), 25. https://doi.org/10.1186/s40594-018-0126-3

Li, Y., \& Schoenfeld, A. H. (2019). Problematizing teaching and learning mathematics as "given" in STEM education. International Journal of STEM Education, 6(1), 44, s40594-019-0197-0199. https://doi.org/10.1186/s40594019-0197-9

Luttenberger, S., Wimmer, S., \& Paechter, M. (2018). Spotlight on math anxiety. Psychology Research and Behavior Management, Volume 11, 311-322. https:// doi.org/10.2147/PRBM.S141421

Maciejewski, W., \& Merchant, S. (2016). Mathematical tasks, study approaches, and course grades in undergraduate mathematics: A year-by-year analysis. International Journal of Mathematical Education in Science and Technology, 47(3), 373-387. https://doi.org/10.1080/0020739X.2015.1072881

Martin-Hansen, L. (2018). Examining ways to meaningfully support students in STEM. International Journal of STEM Education, 5(1), 53. https://doi.org/10. 1186/s40594-018-0150-3

Marton, F., \& Säljö, R. (1976). On qualitative differences in learning: I-Outcome and process. British Journal of Educational Psychology, 46(1), 4-11.

Marton, F., \& Säljö, R. (1984). Approaches to learning. In F. Marton, D. Hounsell, \& N. J. Entwistle (Eds.), The Experience of Learning (pp. 36-55). Scottish Academic Press.

McCrae, R. R., \& Costa, P. T. (2003). Personality in adulthood: A five-factor theory perspective. New York: Guilford Press.

McMullan, M., Jones, R., \& Lea, S. (2012). Math anxiety, self-efficacy, and ability in British undergraduate nursing students. Research in Nursing \& Health, 35(2), 178-186. https://doi.org/10.1002/nur.21460

Mõttus, R., \& Rozgonjuk, D. (2019). Development is in the details: Age differences in the big five domains, facets, and nuances. Journal of Personality and Social Psychology. https://doi.org/10.1037/pspp0000276

Murphy, P. E. L. (2017). Student approaches to learning, conceptions of mathematics, and successful outcomes in learning mathematics. In L. N. Wood \& Y. A. Breyer (Eds.), Success in Higher Education (pp. 75-93). Springer Singapore. https://doi.org/10.1007/978-981-10-2791-8_5

Oberlin, L. (1982). How to teach children to hate mathematics. School Science and Mathematics, 82(3), 261-261. https://doi.org/10.1111/j.1949-8594.1982. tb17187.x

OECD. (2013a). Mathematics self-beliefs and participation in mathematics-related activities. In OECD, PISA 2012 Results: Ready to Learn (Volume III) (pp. 87-112). OECD. https://doi.org/10.1787/9789264201170-8-en

OECD. (2013b). PISA 2012 results: Ready to learn (Volume III): Students' engagement, drive and self-beliefs. OECD. https://doi.org/10.1787/9789264201170-en

OECD. (2014). PISA 2012 technical report. https://www.oecd.org/pisa/pisaproducts/ PISA\%202012\%20Technical\%20Report_Chapter\%2016.pdf. Accessed 24 Apr 2020.

OECD. (2017). What is PISA? In OECD, PISA 2015 assessment and analytical framework (pp. 11-18). OECD. https://doi.org/10.1787/9789264281820-2-en

Paechter, M., Macher, D., Martskvishvili, K., Wimmer, S., \& Papousek, I. (2017). Mathematics anxiety and statistics anxiety. Shared but Also Unshared Components and Antagonistic Contributions to Performance in Statistics. Frontiers in Psychology, 8, 1196. https://doi.org/https://doi.org/10.3389/fpsyg. 2017.01196

Papinczak, T., Young, L., Groves, M., \& Haynes, M. (2008). Effects of a metacognitive intervention on students' approaches to learning and selfefficacy in a first year medical course. Advances in Health Sciences Education, 13(2), 213-232. https://doi.org/10.1007/s10459-006-9036-0

Pelch, M. (2018). Gendered differences in academic emotions and their implications for student success in STEM. International Journal of STEM Education, 5(1), 33. https://doi.org/10.1186/s40594-018-0130-7

Phan, H. P. (2011). Interrelations between self-efficacy and learning approaches: A developmental approach. Educational Psychology, 31(2), 225-246. https://doi. org/10.1080/01443410.2010.545050

Postareff, L., Parpala, A., \& Lindblom-Ylänne, S. (2015). Factors contributing to changes in a deep approach to learning in different learning environments. 
Learning Environments Research, 18(3), 315-333. https://doi.org/10.1007/ s10984-015-9186-1

Prat-Sala, M., \& Redford, Paul. (2010). The interplay between motivation, selfefficacy, and approaches to studying. British Journal of Educational Psychology, 80(2), 283-305. https://doi.org/10.1348/000709909X480563

R Core Team. (2020). R: A language and environment for statistical computing (3.6. 3) [Computer software]. R Core Team.

Revelle, W. R. (2018). psych: Procedures for personality and psychological research. https://CRAN.R-project.org/package=psych

Royse, D., \& Rompf, E. L. (1992). Math anxiety: A comparison of social work and non-social work students. Journal of Social Work Education, 28(3), 270-277. https://doi.org/10.1080/10437797.1992.10778780

Rozgonjuk, D., Saal, K., \& Täht, K. (2018). Problematic smartphone use, deep and surface approaches to learning, and social media use in lectures. International Journal of Environmental Research and Public Health, 15(1). https://doi.org/10. 3390/ijerph15010092

Tobias, S., \& Weissbrod, C. (1980). Tobias, S., \& Weissbrod, C. Anxiety and mathematics: An update. Harvard Educational Review, 50(1), 63-70.

Valk, A., \& Marandi, T. (2005). How to support deep learning at a university. (F. E. H. Tay, T. S. Chuan, \& S. Han-Ming, Eds.; Vol. 200, pp. 191-196). National University of Singapore.

Vinson, B. M. (2001). A comparison of preservice teachers' mathematics anxiety before and after a methods class emphasizing manipulatives. Early Childhood Education Journal, 29(2), 89-94. https://doi.org/10.1023/A:1012568711257

Yamani, M., Almala, A., Elbedour, S., Woodson, K., \& Reed, G. (2018). Math anxiety: Trends, issues and challenges. Journal of Psychology and Clinical Psychiatry, 9(1), 00503

Yusof, Y. bt. M., \& Tall, D. (1998). Changing attitudes to university mathematics through problem solving. Educational Studies in Mathematics, 37(1), 67-82. https://doi.org/10.1023/A:1003456104875

Zan, R., \& Martino, P. (2007). Attitude toward mathematics: Overcoming the positive/ negative dichotomy. The Montana Mathematics Enthusiast, 3(1), 157-168.

\section{Publisher's Note}

Springer Nature remains neutral with regard to jurisdictional claims in published maps and institutional affiliations.

\section{Submit your manuscript to a SpringerOpen ${ }^{\circ}$ journal and benefit from:}

- Convenient online submission

- Rigorous peer review

- Open access: articles freely available online

High visibility within the field

- Retaining the copyright to your article

Submit your next manuscript at $\boldsymbol{\nabla}$ springeropen.com 